\title{
Bladder Neck Morphologic Changes and Clinical Correlation of Smokers Submitted to Radical Prostatectomy
}

\author{
L. C. N. Araujo ${ }^{*}$, W. S. Costa ${ }^{2}$, F. O. Vilar ${ }^{1}$, S. V. C. Lima ${ }^{1}$, F. J. B. Sampaio ${ }^{2}$ \\ ${ }^{1}$ Urology Department, Hospital das Clinicas, Federal University of Pernambuco, PE, Brazil \\ ${ }^{2}$ Urogenital Research Unit, State University of Rio de Janeiro, RJ, Brazil \\ Email: *leslie.clifford@gmail.com
}

Received August 18, 2013; revised August 30, 2013; accepted September 5, 2013

Copyright (C) 2013 L. C. N. Araujo et al. This is an open access article distributed under the Creative Commons Attribution License, which permits unrestricted use, distribution, and reproduction in any medium, provided the original work is properly cited.

\begin{abstract}
Introduction: Smoking is an important risky factor to many diseases, affecting arterial system, skin and urogenital system, including bladder neck stenosis. Its effect on bladder neck has not been described. Objective: Evaluate possible morphological changes caused by nicotine in the bladder neck. Material and Method: Fragments of bladder neck of 16 patients were submitted to stereological analysis, and those patients are divided into two groups, one of smokers and the other of non-smokers with 7 and 9 patients, respectively. After 90 days of surgery, they were submitted to free uroflowmetry and data analyzed by $\mathrm{T}$ test, having statistical significance with $\mathrm{P}<0.05$. Results: An increase of $63.26 \%$ in the amount of fibers in the elastic system of the smokers group was observed, a reduction of $35.96 \%$ in the thickness of arteries, as well as an increase of IPSS and decrease of maximum flow in uroflowmetry, all with statistical significance. Discussion: Laboratorial changes are similar to those found in other studies with different tissues, such as skin, in which those findings are related to premature ageing. Clinical results, though statistically significant, do not have clinical consistence because the study was meant to morphological analysis. Conclusion: Smoking increases the amount of fibers in the elastic system and decreases the thickness of bladder neck arteries.
\end{abstract}

Keywords: Smoking; Bladder Neck; Elastic Fibers; Uroflowmetry

\section{Introduction}

Smoking has been described as an important risky factor to many diseases. It is closely linked to heart diseases, affecting directly the arterial system and microvasculature [1-4], and it also affects the distribution of extracellular matrix related to early ageing of these tissues [5-7]. In urogenital tract, it is linked to the development of bladder and prostate cancers and erectile dysfunction. Epidemiologically, it is a risky factor to bladder neck sclerosis following radical prostatectomy [1,8-14].

Morphological evaluation of bladder neck of smokers, as well as its clinical repercussions, has not been described yet.

\section{Objective}

The aim of this study is to analyze the possible morphological bladder neck changes of smokers and non-smok-

${ }^{*}$ Corresponding author. ers submitted to radical prostatectomy and compare those findings with laboratorial and clinical data obtained.

\section{Material and Method}

The Project was submitted to the Ethics Committee of the involved institution. Patients signed the form of free and duly informed consent. The calculus of the number of elements in the sample was done through standard deviation and margin of error, considering $\mathrm{P}<0.05$, and then obtaining the number of cases necessary to the comparison of two groups of patients, that had the amount of 6.65 for all parameters in each group.

Sixteen patients were selected, ages 62 to 69, all Navy military retirees and residents in Rio de Janeiro without prior prostate disease or vascular co-morbidities, which were undergone to radical prostatectomy. During the surgery fragments were taken from this group of patients, measuring approximately $1 \mathrm{~cm}$, from the anterior surface of the bladder neck. The collection of material was done 
after the prostate and the seminal vesicles were removed and before vesicourethral anastomosis. Those patients were split in two groups, smokers (7 patients) and non-smokers ( 9 patients).

Patients that had surgical vesicle margin positive to oncological impairment or those submitted to radiotherapy as therapeutic complementation were excluded from the sample.

The material obtained was fixed in formalin solution (pH 7.2) and processed according to the histological routine stages to inclusion in paraffin. The material was cut with a width of $5 \mu \mathrm{m}$.

The sections were stained by the following techniques: hematoxylin and eosin to tissue integrity analysis and arterial wall width measurement; oxidized Weigert's resorcin-fuchsin to characterize elastic system fibers and Van Gieson's to analyze collagen fibers and smooth muscle cells. After histologic routine procedures, sections were photographed in microscopic computerized system, composed of optical microscope and camera (Olympus ${ }^{\circledR}$ ).

The quantification of different elements analyzed was done using Image ${ }^{\circledR}$ program (Image Processing and Analysis in Java).

All patients were clinically followed-up for 180 days after surgery, filling up IPSS questionnaire (International Prostate Score Symptoms) [15] and were submitted to free uroflowmetry tests.

Results obtained were analyzed by statistical program GraphPad Prism 4, through unpaired two-tailed Student's $\mathrm{T}$ test, as well as through Pearson correlation analysis between gross amount results with calculus via confidence interval. Results were considered significant when $\mathrm{P}<0.05$.

\section{Results}

All data assumed normal distribution and the following results were obtained: in the smokers' group the amount of collagen fibers was $22.70 \%(\mathrm{SD}=4.86)$, elastic system fibers $13.29 \%(\mathrm{DP}=3.84)$ (Figure 1), smooth muscle $23.97 \%$ ( $\mathrm{SD}=12.3)$, height of arterial wall was 16.52 $\mu \mathrm{m}(\mathrm{SD}=2.73)$ (Figure 2), while in the non-smoker's group was $21.20 \%(\mathrm{SD}=8.21)$ to collagen fibers, $8.14 \%$ $(\mathrm{SD}=3.54)$ to elastic system fibers, $23.97 \%(\mathrm{SD}=8.01)$ (Figure 3) to smooth muscle fibers and $25.80 \mu \mathrm{m}(\mathrm{SD}=$ 7.18) to height of arterial wall (Figure 4).

As for the parameters of clinical analysis, smokers' IPSS had an average of $18.40(\mathrm{SD}=5.58)$, and nonsmokers' was $9.39(\mathrm{SD}=3.73)$, maximun flow obtained in free uroflowmetry (Qmax) had an average of $4.80 \mathrm{ml} / \mathrm{s}$ $(\mathrm{DP}=1.72)$, and $9.60 \mathrm{ml} / \mathrm{s}(\mathrm{SD}=3.20)$ for non-smokers.

Statistical analysis showed that the increase in the amount of collagen fibers and the decrease of smooth muscle fibers had no statistical significance $(P>0.05)$. However the increase of the amount of elastic system

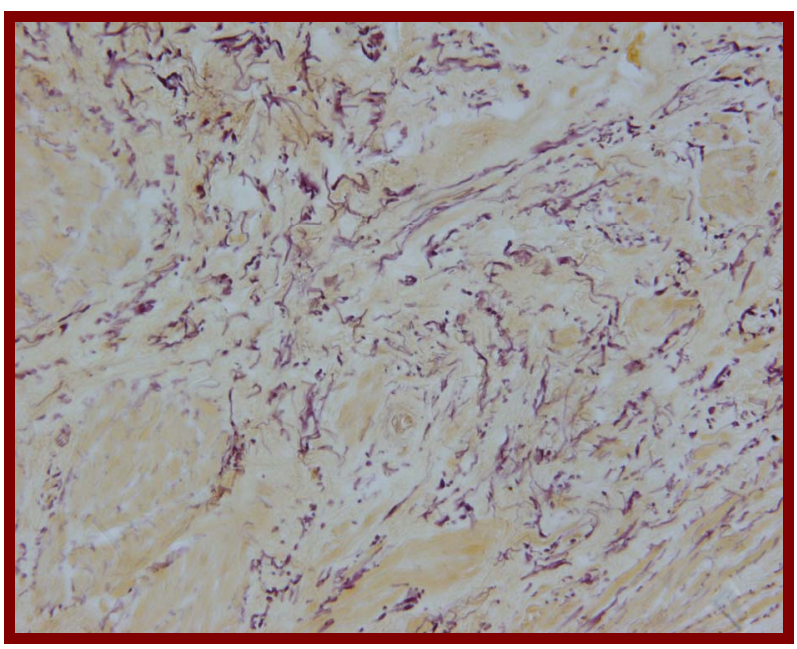

Figure 1. Photomicrography smoker group Weigert's resorcin-fuchsin, $400 \times$.

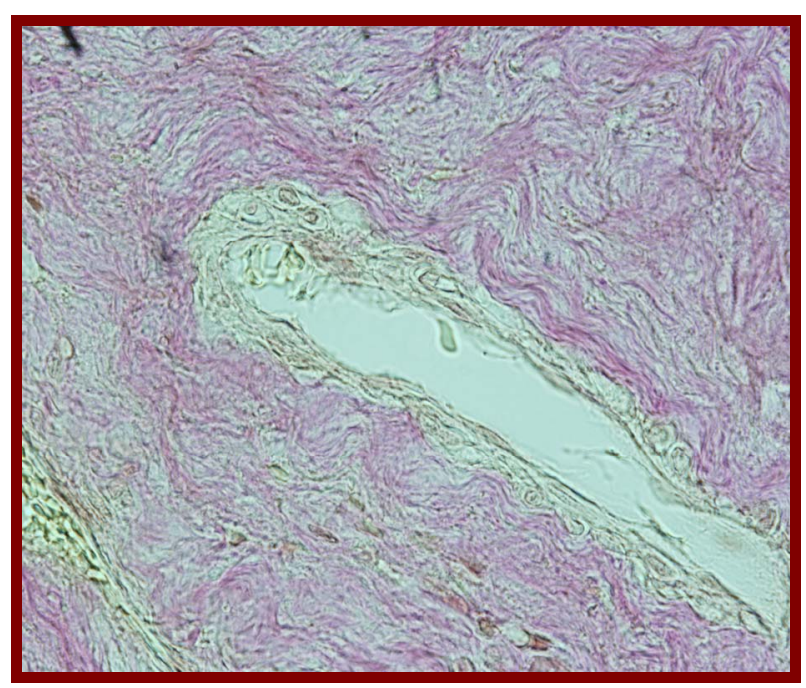

Figure 2. Arterial Wall, smoker Group, Van Gieson, 400×.

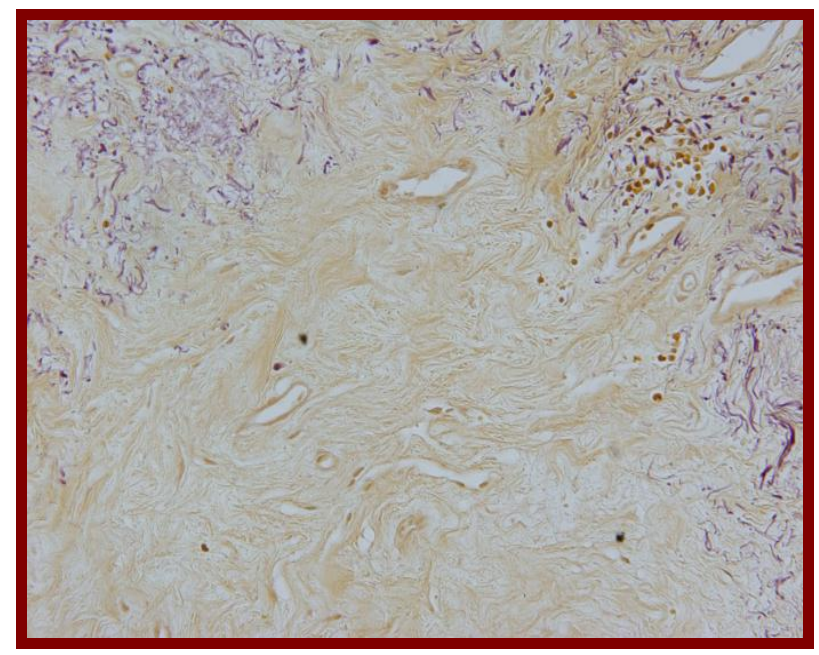

Figure 3. Photomicrography nonsmoker group Weigert's resorcin-fuchsin, $400 \times$. 


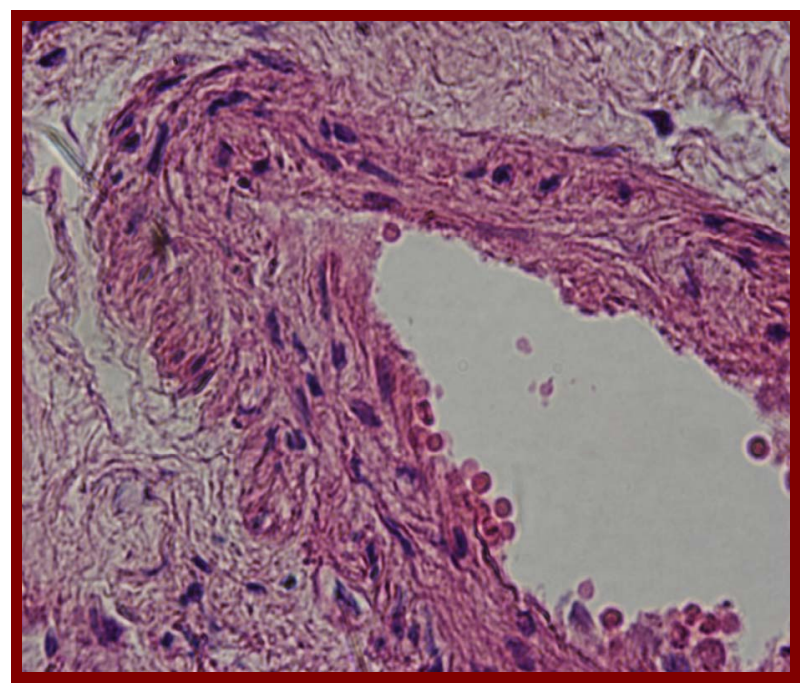

Figure 4. Arterial Wall, non-smoker Group, H \& E, 400×.

fibers and the decrease of height of arterial wall in the same group had $\mathrm{P}<0.05$.

Through clinical analysis it was perceived increase of IPSS and decrease of Qmax, both with statistical significance $(\mathrm{P}<0.05)$, in the smokers group.

Correlation analysis showed $\mathrm{R}=-0.67(\mathrm{P}<0.05)$ between the amount of elastic system fibers and height of arterial wall, $\mathrm{R}=0.55(\mathrm{P}<0.05)$ between amount of elastic system fibers and IPSS, $\mathrm{R}=-0.54(\mathrm{P}<0.05)$ between elastic system fibers and Qmax, $R=-0.59$ between height of arterial wall and IPSS, $\mathrm{R}=0.47(\mathrm{P}=$ 0.06 ) between height of arterial wall and $\mathrm{Qmax}$, and $\mathrm{R}=$ $-0.94(\mathrm{P}<0.05)$ between IPSS and Qmax.

Four patients in each group developed cardiovascular diseases, but no statistical difference was found when compared with the averages of the group that did not developed obstructive pathology.

Numerical results of different parameters can be seen on Tables 1 to 3 .

\section{Discussion}

Effects of tobacco consumption on bladder neck circulation had not been previously characterized in literature. Borboroglu in 2000 evaluated patients that had sclerosis of bladder neck anastomosis among those risky factor groups: chronic obstructive lung disease (COLD), coronary arterial disease (CAD), Diabetes Mellitus (DM), smoking, pre-operative blood loss, surgical time and previous history of transurethral prostate resection (TURP) and concluded that smoking is an important factor to the development of sclerosis of bladder neck anastomosis, suggesting that it is originated from micro vascular changes [10]. Mack et al. (2003) observed a decrease of thickness of carotid artery as consequence of chronic use of nicotine [4].
Table 1. Morphometry of smooth muscle collagen, elastic system fibers and width of arterial wall-average \pm standard deviation. Arterial wall width in $\mu \mathrm{m}$.

\begin{tabular}{cccc}
\hline & smoking & non-smoking & P \\
\hline Collagen \% & $22.70 \pm 4.86$ & $21.20 \pm 8.21$ & $\mathbf{0 . 9 0 4}$ \\
Smooth Muscle \% & $23.97 \pm 12.31$ & $27.97 \pm 8.02$ & $\mathbf{0 . 3 3 8}$ \\
Elastic Fiber \% & $13.29 \pm 3.85$ & $8.14 \pm 3.54$ & $\mathbf{0 . 0 2 0}$ \\
Arterial Wall $(\boldsymbol{\mu m})$ & $16.52 \pm 2.73$ & $25.80 \pm 7.19$ & $\mathbf{0 . 0 0 5}$ \\
\hline
\end{tabular}

Table 2. Clinical analysis. IPSS (International Prostate Score Symptoms) and Qmax (maximum flow).

\begin{tabular}{cccc}
\hline & smoking & non-smoking & P \\
\hline IPSS & $18.40 \pm 5.59$ & $9.67 \pm 3.73$ & $\mathbf{0 . 0 0 4}$ \\
Qmax & $4.80 \pm 4.72$ & $9.45 \pm 3.20$ & $\mathbf{0 . 0 4 0}$ \\
\hline
\end{tabular}

Table 3. Analysis of Pearson correlation. Morphometry and Clinical Analysis. International Prostate Score Symptoms (IPSS); Free Uroflowmetry (Qmax).

\begin{tabular}{ccc}
\hline Pearson Correlation & $\mathbf{R}$ & $\mathbf{P}$ \\
\hline Elastic X Arterial Wall & -0.67 & $<\mathbf{0 . 0 5}$ \\
Elastic X IPSS & 0.55 & $<\mathbf{0 . 0 5}$ \\
Elastic X Qmax & -0.52 & $<\mathbf{0 . 0 5}$ \\
Arterial Wall X IPSS & -0.57 & $<\mathbf{0 . 0 5}$ \\
Arterial Wall X Qmax & 0.44 & $>\mathbf{0 . 0 5}(\mathbf{p}=\mathbf{0 . 0 6})$ \\
\hline
\end{tabular}

In this study, there were no findings of significant differences between the two groups when compared the amount of collagen and smooth muscle fibers. The reports of changes in synthesis and deposit of collagen from instillation of 7H-dibenzol (c, g) carbazole, that is a component of tobacco, represent specific changes of the respiratory tract, trachea and bronchi, in progressive neoplasia during the process of tumoral induction [16]. In this case tobacco action is not direct and, therefore, the effects are presented in a different way of those found in lungs, which explains conflicting results with previous studies.

The decrease of bladder neck arterial wall thickness in $35.96 \%$ (Figures 3 and 4) is conformed to literature, in which nicotine consumption is risky factor to atherosclerosis, thrombosis, tissue injury, superoxide ions and free radicals formation, reducing production and availability of Nitric Oxide, increasing the production of endothelin, leading to endothelial dysfunction, thrombosis, atherosclerosis and other endothelial diseases $[3,17,18]$, decreasing elasticity of large arteries $[4,17,19]$, with consequent organization disturbances, stiffness, calcification and vasomotor dysfunction [20], which are directly related to decrease of tissue oxygenation [21]. Even though Raveendran et al, 2004, have related these changes to collagen metabolism [22], our results indicate that there is a change in elastic system fibers metabolism through 
changes in the production and metabolism of metalloproteinase $[5,6]$, confirmed by statistical correlation between thickness and amount of bladder neck elastic fibers (Table 3).

In vitro studies indicate that tobacco consumption prevents collagen production and increases tropoelastin production and activation of metalloproteinase, causing a degradation of matrix proteins and a abnormal production of elastic material, in its morphology and amount, having as a consequence the increase of the number of elastic system fibers in the skin [4-6]. In our results we have seen an increase of $62.36 \%$ of elastic system fibers in bladder neck tissue in smokers group when compared to non-smokers (Figures 1 and 2). Morita, associated these findings to early skin ageing [6].

Effect of smoking on the arterial system and consequent formation of elastic system fibers may not be limited to bladder neck, being distributed in all bladder, with an increase of elastic system fibers in all bladder wall and its repercussions, being able to cause early ageing, but there are no ways of getting definitive conclusions, once there are no previous data in the literature on bladder ageing.

Not with standing the results in clinical data have been statistically significant, they should be viewed with restrictions mainly by the number of participants and the absence of data related to detrusor function provided by uroflowmetry, once the study design was not meant to morphological evaluation only, and as such there are no previous data of bladder function in smokers. Gathered data may be, in spite of statistical significance, a coincidence, and are necessary future clinical studies to confirm the present findings. Results will be discussed only in order to be compared to further.

Results found on clinical data supposedly indicated an impact related to tobacco consumption both in IPSS result, with an increase of approximately $93 \%$, as in Qmax reduction, with a decrease of about $51 \%$, which was reflected in a reduction of voiding function statistically significant in smokers when compared to those that were not exposed to nicotine.

Correlation analysis between quantitative data and clinical results shows that there can be a strong connection between clinical changes related to amount of elastic system fibers. Even though there is a great limitation of data, which leads to absence of definitions regarding detrusor behavior, as for number of specimens, there should be a supposed early ageing that can happen to bladder tissue as well as skin [6], which should explain the changes that were found, with a probable reduction in detrusor contractility, as results are related to smoking and not with existence of cardiovascular diseases. But stating a definitive conclusion will only be possible with studies that evaluate detrusor function.

\section{Conclusions}

In the present study, smoking modified bladder neck extra-cell matrix of patients submitted to radical prostatectomy with an increase of the amount of elastic system fibers $(\mathrm{P}<0.05)$.

It is also observed a decrease of arterial wall height in the same group with statistical correlation $(\mathrm{P}<0.05)$.

\section{REFERENCES}

[1] S. T. Hanna, "Nicotine Effect on Cardiovascular System and Ion Channels," Journal of Cardiovascular Pharmacology, Vol. 47, No. 3, 2006, pp. 348-358.

[2] U. John, S. E. Baumeister, C. Kessler and H. Volzke, "Associations of Carotid Intima-Media Thickness, Tobacco Smoking and Overweight with Hearing Disorder in a General Population Sample," Atherosclerosis, Vol. 195, No. 1, 2007, pp. e144-e149.

http://dx.doi.org/10.1016/j.atherosclerosis.2007.04.007

[3] N. Lindenblatt, U. Platz, J. Hameister, E. Klar, M.D. Menger and B. Vollmar, "Distinct Effects of Acute and Chronic Nicotine Application on Microvascular Thrombus Formation and Endothelial Function in Male and Female Mice," Langenbeck's Archives of Surgery, Vol. 392, No. 3, 2007, pp. 285-295. http://dx.doi.org/10.1007/s00423-007-0173-6

[4] W. J. Mack, T. Islam, Z. R. H. Lee, Selzer, et al., "Environmental Tobacco Smoke and Carotid Arterial Stiffness," Preventive Medicine, Vol. 37, No. 2, 2003, pp. 148-154.

http://dx.doi.org/10.1016/S0091-7435(03)00097-5

[5] M. Just, Ribera, M. Monso, E. Lorenzo, J. C. Lorenzo and C. Ferrándiz, "Effect of Smoking on Skin Elastic Fibres: Morphometric and Immunohistochemical Analysis," British Journal of Dermatology, Vol. 156, No. 1, 2007, pp. 85-91.

http://dx.doi.org/10.1111/j.1365-2133.2006.07575.x

[6] A. Morita, "Tobacco Smoke Causes Premature Skin Aging," Journal of Dermatological Science, Vol. 48, No. 3, 2007, pp. 169-175. http://dx.doi.org/10.1016/i.jdermsci.2007.06.015

[7] H. Tanaka, Y. Ono, Y. Nakata, N. Shintani, et al., "Tobacco Smoke Extract Induces Premature Skin Aging in Mouse," Journal of Dermatological Science, Vol. 46, No. 1, 2007, pp. 69-71. http://dx.doi.org/10.1016/j.jdermsci.2006.11.009

[8] G. D. Batty, M. Kivimaki, G. D. Gray, M. G. Smith, et al., "Cigarette Smoking and Site-Specific Cancer Mortality: Testing Uncertain Associations Using Extended Follow-up of the Original Whitehall Study," Annals of Oncology, Vol. 191, No. 5, 2008, pp. 996-1002.

[9] S. Boorjian, J. E. Cowan, B. R. Konety, J. DuChane, et al., "Bladder Cancer Incidence and Risk Factors in Men with Prostate Cancer: Results from Cancer of the Prostate Strategic Urologic Research Endeavor," Journal of Urology, Vol. 177, No. 3, 2007, pp. 883-887.

[10] P. G. Borboroglu, J. P. Sands, J. L. Roberts and C. L. 
Amling, "Risk Factors for Vesicourethral Anastomotic Stricture after Radical Prostatectomy," Urology, Vol. 56, No. 1, 2000, pp. 96-100. http://dx.doi.org/10.1016/S0090-4295(00)00556-2

[11] K. Hickey, K.-A. Do and A. Green, "Smoking and Prostate Cancer," Epidemiologic Reviews, Vol. 23, No. 1, 2001, pp. 115-125. http://dx.doi.org/10.1093/oxfordjournals.epirev.a000776

[12] J. K. Parsons, "Modifiable Risk Factors for Benign Prostatic Hyperplasia and Lower Urinary Tract Symptoms: New Approaches to Old Problems," Journal of Urology, Vol. 178, No. 2, 2007, pp. 395-401. http://dx.doi.org/10.1016/j.juro.2007.03.103

[13] J. Y. Polsky, K. J. Aronson, J. P. W. Heaton and M. A. Adams, "Smoking and Other Lifestyle Factors in Relation to Erectile Dysfunction," BJU International, Vol. 96, No. 9, 2005, pp. 1355-1359. http://dx.doi.org/10.1111/j.1464-410X.2005.05820.x

[14] F. Sommer and M. J. Mathers, "Lifestyle, Erectile Dysfunction, Hormones and Metabolic Syndrome. Opportunities for Gender-Specific Prevention for Men," Urologe A, Vol. 46, No. 6, 2007, pp. 628-635.

[15] N. Rodrigues Netto, M. L. de Lima, E. F. M. de Andrade, F. Apuzzo, et al., "Latin American Study on Patient Acceptance of the International Prostate Symptom Score (IPSS) in the Evaluation of Symptomatic Benign Prostatic Hyperplasia," Urology, Vol. 49, No. 1, 1997, pp. 46-49. http://dx.doi.org/10.1016/S0090-4295(96)00372-X

[16] J. Laitakari and F. Stenback, "Collagen Matrix in Development and Progression of Experimentally Induced Respiratory Neoplasms in the Hamster," Journal of Toxicologic Pathology, Vol. 29, No. 5, 2001, pp. 514-527. http://dx.doi.org/10.1080/019262301317226311

[17] M. M. Rahman and I. Laher, "Structural and Functional
Alteration of Blood Vessels Caused by Cigarette Smoking: An Overview of Molecular Mechanisms," Current Vascular Pharmacology, Vol. 5, No. 4, 2007, pp. 276-292. http://dx.doi.org/10.2174/157016107782023406

[18] C.-W. Shen, Y.-H. Wang, Y.-C. Jou, et al., "Inducible Nitric Oxide Synthase Promoter Polymorphism, Cigarette Smoking, and Urothelial Carcinoma Risk," Urology, Vol. 69, No. 5, 2007, pp. 1001-1006. http://dx.doi.org/10.1016/j.urology.2007.02.028

[19] H. Yin, L. Chao and J. Chao, "Nitric Oxide Mediates Cardiac Protection of Tissue Kallikrein by Reducing Inflammation and Ventricular Remodeling after Myocardial Ischemia/Reperfusion," Life Sciences, Vol. 82, No. 3-4, 2008, pp. 156-165. http://dx.doi.org/10.1016/j.1fs.2007.10.021

[20] A. W. Y. Chung, H. H. C. Yang, J. M. Kim, M. K. Sigrist, et al., "Upregulation of Matrix Metalloproteinase-2 in the Arterial Vasculature Contributes to Stiffening and Vasomotor Dysfunction in Patients with Chronic Kidney Disease," Circulation, Vol. 120, No. 9, 2009, pp. 792-801. http://dx.doi.org/10.1161/CIRCULATIONAHA.109.8625 $\underline{65}$

[21] H. Gullu, M. Caliskan, O. Ciftci, D. Erdogan, et al., "Light Cigarette Smoking Impairs Coronary Microvascular Functions as Severely as Smoking Regular Cigarettes," Heart, Vol. 93, No. 10, 2007, pp. 1274-1277. http://dx.doi.org/10.1136/hrt.2006.100255

[22] M. Raveendran, D. Senthil, B. Utama, Y. Shen, et al., "Cigarette Suppresses the Expression of P4Halpha and Vascular Collagen Production," Biochemical and Biophysical Research Communications, Vol. 323, No. 2, 2004, pp. 592-598.

http://dx.doi.org/10.1016/j.bbrc.2004.08.129 